\title{
Beyond Professionalism to Leadership: Leveraging Leadership for a Lifetime
}

\author{
Elaine Millam, Ronald J. Bennett, Ph.D. \\ Engineering and Technology Management \\ University of St. Thomas \\ St. Paul, Minnesota
}

\begin{abstract}
In 2000, our Industry Advisory Board asked how we knew that we were achieving our mission, how could we determine that our students were becoming the leaders as we claimed and, further, how would we know what our program was contributing to student personal growth? The ensuing discussion among industry representatives, faculty and students on what it meant to be "professional" and a "leader" resulted in the creation of a three-part course in our Master of Science in Technology Management degree program. The three parts - one at the beginning, middle and end of the degree program, were designed to determine the students' initial leadership capacities and then engage the student in more self-awareness assessment, planning and developing a learning roadmap. Finally, we would show how the students had grown their capacities throughout the program.
\end{abstract}

At the onset of the program, students are assessed on their emotional capacity, their leadership characteristics, their personality inventory, competencies that align with program objectives and their life-learning process. The resulting assessment profile helps the student to plan for their graduate program-learning journey. They intentionally set forth a roadmap and identify a network that will support their learning throughout the program, using key faculty, friends and business colleagues on-the-job to enhance their learning agenda. They come to recognize themselves as leaders in the making. They make commitments to themselves for how they intend to develop on-the-job as well as on the campus and in their communities.

Throughout the learning process, they have checkpoints built in to re-assess themselves and witness their progress. They focus their leadership journey on self, their team, their organizations and their intended contributions. By the end of the program, they receive feedback from all stakeholder groups who are witnessing their progress and commenting on their results. 
Students so far are excited about their learning pursuits, engaging others to support them and are demonstrating their leadership talents as they learn, stretch and grow. They feel real strength and power in coming to better understand themselves and taking charge of their own learning outcomes. We, as faculty, are prepared to support their journeys and wonder with them about their lifelong possibilities.

\section{$\underline{\text { Mission }}$}

We provide a practical, values based learning experience that produces well-rounded, innovative engineers and technology leaders who have the technical skills, passion and courage to make a difference.

\section{$\underline{\text { Background }}$}

After many years of offering Masters degrees in engineering and operations, we identified a need for a new type of degree in our market to serve the needs of individuals in organizations where technology was changing rapidly. The knowledge and skills needed in this challenging environment called for creating a new program that dealt specifically with unarticulated customer needs, change, risk, courage and leadership. In response to that need we created the Master of Science in Technology Management (MSTM) in 1997.

When the MSTM program was created, we established specific program objectives and educational outcomes which can be found on our website listed in the bibliography. We also put in place a well-defined process for admitting students to the program. The objective of this process was to ascertain that the MSTM program was a good fit for each student, and that the students resonated with the objectives of the program. Required for admission were: 1) a goal statement, 2) a letter of endorsement from their manager and 3) a personal interview with the Program Director to review student and program goals and engage in a discussion to establish expectations of student and program.

Among the expectations of the student are 1) to have a mentor and 2) to take learning from each course back into their organization. The role of the mentor and mentee are outlined and methods of taking learning back into their organizations are discussed. The goal in both cases is to help the students develop their leadership potential, give the students visibility in their organizations to a wide audience, helping them establish their expertise and initiative and bring value to themselves and their organizations. Students respond very favorably to this process and the goals.

Periodic breakfast, lunch and dinner meetings have enhanced these methods with students and their mentors that began in 1998. Resources on mentoring have been provided at these meetings, and an atmosphere of discussion and sharing among students and mentors has resulted in energetic and stimulating conversation. 
Still, we knew more could be done to help the students take full advantage of their learning and more fully develop their leadership skills.

\section{Enter the Industry Advisory Board}

In 2000, our Industry Advisory Board was reviewing the Program Objectives and Mission and asking the question, "How can we measure whether these goals are being achieved?" and "Is our program making a difference?" This discussion of assessment also ranged into a discussion of the definition of leadership and professionalism.

Built on the ideas expressed in our Mission, Program Objectives and definition of leadership, a draft of an approach was created in 2000 and reviewed by faculty. In early 2002, we also undertook a benchmarking initiative of six other universities, searching for best practices that might assist in this process. These benchmarking visits provided ideas that we incorporated into our plan for a new approach to assessing the effectiveness of our MSTM program.

After considerable discussion, revision and refinement, a proposal was submitted to our Graduate Curriculum Committee in 2002 fro a new three-part course titled "Leveraging Leadership for a Lifetime". The course was unanimously approved.

This sequence of three one-credit courses, spread throughout the full MSTM degree program, is designed to provide the student with an ongoing close look at herself/himself as a learner, a leader, and the person in charge of her/his life-long plan. The series intends to answer the question, "How do I get the best possible results for my life goals from this graduate program?"

\section{Development of the Leadership Series}

A Design Committee including key faculty and other department staff worked together to clearly articulate the intentions for the Leveraging Leadership for a Lifetime (LLL) wrap around the MSTM Program. They identified specific learning outcomes for the leadership series, critical features for the process and expected outcomes for each of the courses. We used a set of critical design assumptions as our guide for development. These assumptions were based on adult learning theory as well as motivational theory. Furthermore, we felt the student should take personal responsibility to be actively involved in their learning agenda, shape a vision for his/her leadership and learning that would guide their planning process while they deliberately focused on increasing their self-awareness and understanding of a leader's social/ethical responsibilities.

The three-course series would begin with a thorough base-line assessment of the individual graduate student's competencies, personal values, learning style, leadership aptitude and other data (both qualitative and quantitative) regarding their personality profile and emotional intelligence. Each of these areas was seen as a critical ingredient contributing to the leadership capacity building process. The student would use the data as a foundational building block in designing their roadmap for learning and leading. 
Several instruments were reviewed and carefully selected that would provide reliable and valid measures of each of these areas. Each student would engage with others in his/her workplace to gather feedback and inputs that would give him/her others' perceptions of their leadership characteristics and capabilities. Some of these same people were invited to be ongoing supports for the student's learning process, continually providing feedback on demonstrated progress. Key support people include a mentor selected by the student, most often from his/her workplace, the students' advisor and others who work closely with the student.

The initial course within the series sets the stage for the 3-5 yearlong learning process. The students spend time shaping their own vision and accompanying plan for how they will integrate all their classroom learnings, their work experiences and their personal inventories to reach their desired vision for their graduate program. They identify key players who will serve as their personal and professional Board of Directors. They determine how they will use this Board, and build an action plan for achieving each of the milestones along the way.

Tom is a dynamic, entrepreneurial student in the program who has his sights set on launching his own business. He currently serves as an Engineering Director in a Power Plant facility. He knows he has the capacity to grow his strategic leadership prowess and wants to build an empowering workplace that will align people with his vision of making his company attractive and profitable. Some of his milestones for achieving his goals, include expanding his present responsibilities to include more strategic planning and directing, to demonstrate effective lateral team building in his organization and gain financial expertise in order to feel nimble with crafting and executing his business plan. He exudes energy and determination, knows how to enroll others to get excited about his vision and openly welcomes coaching support for building an ambitious timetable for accomplishing each step along the way. He knows where he is headed and has the courage to confront any obstacles along the way.

\section{Launch: The First Phase and Students' Responses}

In January of 2003, the first class of 22 students began the series of LLL courses. The students represented a broad array of occupations and industries including IT, manufacturing, banking, law, public government, medical technology, product design and development, electrical engineering and engineering management to name a few. The students were invited immediately to work in small teams to share experiences, identify common goals and shape their notions of leadership for their graduate program outcomes.

Each student received data from five separate assessment processes-leadership potential, emotional intelligence, personality preferences, learning styles and competencies reflecting MSTM program objectives. Students carefully reviewed their data, looked for correlations across the data and began to shape goals for their learning process that would enhance their strengths and eliminate gaps between their ideals and their present capabilities. 
Through interactive explorations (individual and small groups), they shaped a collective definition of leadership, received interpretative guidance on four of the assessment instruments, assessing strengths, talents, values and learning styles. All of this was integrated with leadership and learning theory to shape an individualized plan of action. The plan flowed naturally from their uniquely articulated vision for the kind of leader the student had chosen as their ideal. This expressed vision and accompanying roadmap was articulated in a final writing assignment as well as a presentation to fellow classmates.

Students learned coaching skills to help one another identify appropriate milestones to accomplish their goals, both personal and professional. The final session in the class became a forum for sharing their proposed plans, sharing how they would hold themselves accountable and how they proposed to use their support structure.

Students feel extremely positive about their initial experience in the series. Many say, "I can't wait for next class...this was the best class I've ever had." Other typical responses to this first session are:

"I loved learning about myself and realize I have more leadership skills than I thought I did."

"This was a friendly, optimistic, positive, wonderful experience!"

"This course was a perfect introduction to the program and also provided me with knowledge that I can immediately use in my personal and professional life."

\section{$\underline{\text { Present Situation }}$}

Since the initial launch, 51 students have completed the first of the required series of Leveraging Leadership for a Lifetime courses. Each of these students are presently working with their mentors, advisors and Board of Directors to follow their plan of action to become a more intentional leader in their workplace, their social environments and their families. There is excitement, high energy and serious commitment.

Several of these students have completed approximately five other courses within their graduate programs and are now registered for the second of the series of LLL. In this second course, the students will review and measure their progress in all areas, will adjust their learning plans accordingly, expanding their leadership capacity building to include team effectiveness and organizational influence. Their leading and learning plan adjustments will reflect the integration of new knowledge and lessons from experience. The students will be asked to continually update their plans to reflect new learning, new progress and new information about themselves.

Much remains to be done in order to know the overall impact of this innovative design. Questions abound such as: 
Will students find creative ways to support each other, use their support structure, seek and give feedback, hold themselves accountable? How will this get demonstrated, monitored and measured?

Will students take responsibility for their learning commitments? Will they establish a practice field within their work environments to test their skills and newfound capabilities? How will they document their learnings?

How will mentors, advisors, students and faculty collaborate to support the students' plans?

Will the UST faculty be able to more explicitly identify which variables truly make the difference for a student?

\section{$\underline{\text { Future Directions }}$}

As we look to the future, we have some hunches about overall outcomes. One would naturally expect that those students who truly use their support structure (Board of Directors and others) will have accelerated learning and growth. Those who value the experiences embedded in their leadership and learning journey, track their progress and learn from it will be motivated to continue to grow and learn beyond their graduate program experience.

It is our intention to continue to monitor the individual and collective outcomes as the students move forward in their learning pursuits. Documentation of results will be important in order to understand what is working well and why as well as what might be improved. The student will play a key role in this process, reflecting on their experience both on-the-job and in the classroom and providing ongoing feedback. A focus on documenting the students' stories of real-time learning and leading will help everyone know just how this process will affect life-long results.

Bibliography

Goleman, Daniel, Boyatzis, Richard and McKee, Annie. Primal Leadership: Realizing the Power of Emotional Intelligence. Boston, Massachusetts: Harvard Business School Press, 2002.

Loehr, Jim and Schwartz, Tony. The Power of Full Engagement. New York: The Free Press, 2003.

Owen, Hilarie. In Search of Leaders. New York: John Wiley \& Sons, 2000.

University of St. Thomas MSTM Program Objectives and Educational Outcomes http://www.stthomas.edu/technology/GRAD/ETM PgmObjectives.htm.

Vaill, Peter B. Learning as a Way of Being. San Francisco: Jossey Bass, 1996. 
Vaill, Peter B. Spirited Leading and Learning. San Francisco: Jossey Bass, 1998.

\section{Biographical Information}

ELAINE MILLAM is an adjunct faculty member in the Engineering \& Technology Management graduate program at the University of St. Thomas. She presently owns and runs her own coaching and consulting firm, following over 30 years of leadership experience in the corporate world-most recently as Director of Individual and Organizational Effectiveness at Honeywell. She currently coaches executives, provides consultation to leadership teams in business and helps organizations navigate through positive change.

RONALD J. BENNETT is Director and Chair of the Engineering Programs at the University of St. Thomas. He holds a Ph.D. in Metallurgical Engineering and an MBA. With a background of 20 years in industry, Bennett teaches and publishes on diverse topics including materials engineering, technical innovation, technology transfer and engineering education. He is an EAC of ABET program evaluator and is currently Chair of the Graduate Studies Division of ASEE. 